\title{
CHINESE CULTURAL VALUES AS A PART OF “BELT AND ROAD INITIATIVE" PROJECT
}

\author{
Fei Xie \\ Lishui University, PR China \\ Nataliia Kalashnyk \\ Donetsk Regional Institute of Postgraduate Pedagogical Education, Ukraine \\ Zhenxuan Fan \\ H.S.Skovoroda Kharkiv National Pedagogial University, PR China \\ Oksana Mkrtichan \\ H.S.Skovoroda Kharkiv National Pedagogial University, Ukraine \\ Valeriia Hryhorenko \\ H.S.Skovoroda Kharkiv National Pedagogial University, Ukraine
}

\begin{abstract}
The Belt and Road Initiative (BRI) is a global development strategy adopted by the Chinese government in 2013. Some experts believe that this project is an attempt to spread Chinese dominance in the region and adjacent territories through the economical initiative. But together with the economic purposes, the BRI aims spreading the Chinese cultural and citizenship values over the local cultures of the countries involved by forming a common cultural space. This article aims to show how the Chinese government uses the BRI Project to demonstrate the achievements of Chinese society in social and cultural life, introduce the modern China to the world, level stereotypes about the Chinese worldview and lifestyle, which were formed in the world due to a certain isolation of China, lack of reliable information about China in the world and some other reasons. At the article the following methods, typical for theoretical research, were used: observation, analysis, synthesis, analogy, comparing, narration, conclusion making etc. The result of the research is the summation of implicit information and the confirmation of the hypothesis that this project is of great cultural importance (to familiarize the world with modern China and its socio-cultural achievements more than in the opposite direction) and uses a wide range of tools to achieve goals.
\end{abstract}

Keywords: "Belt and Road Initiative"(BRI) Project, China, citizenship values, culture, economics, social values, traditions.

\section{Introduction}

The Belt and Road Initiative (BRI) was introduces in 2013 by China as a global development strategy involving infrastructure development and investments for 152 countries and international organizations. The leader of the People's 
Republic of China, Xi Jinping, originally announced the strategy during official visit to Indonesia and Kazakhstan in 2013 (Kuo \& Kommenda, 2018). The initiative aims to join all the Project members by organizing a common transport system (railway + seaway), which, as a belt, "rings" the Eurasian continent. The most used name for the Project is «One Belt One Road» (OBOR) where under the "Belt" is recognized the overland routes for rail transportation (also called "New Silk Road Economic Belt»). The word "Road" refers to the sea routes, also known as "Century Maritime Silk Road". It should be mentioned, that the Project name "One Belt, One Road" also can be seen as a not quite correct translation from the Chinese. (Kuo \& Kommenda, 2018). Originally the phrase “一带一路” got the mistranslation because the word "一"can be translated from the Chinese not only as "one", but also as "common". It is this idea of community that is dominant for the Chinese vision of this Project, especially in terms of the cultural and social space that should accompany its functioning. For today in the literature and mass media the following names can be met: OBOR (One Belt One Road) Project, BRI (Belt and Road Initiative) Project, «New Great Silk Road» Project, New Silk Road Civilization. The above mentioned terms are synonymous and are used in parallel to designate the Project in general as well as its separate components (geo-economic and socio-cultural).

The BRI Project has both its critics and active followers. Some experts believe that this project is an attempt to spread Chinese dominance in the region and adjacent territories through the economical initiative. Others believe that it corresponds to the idea of the economic globalization, which leads to simplification (and, therefore, activation of international trade process). At the same time, the idea of preserving the socio-cultural aspect of the Project's activity, which is achieved by joint ownership and organization of the Project's infrastructure by all of its participants provision, is noted as an undeniable bonus.

The project has a targeted completion date of 2049, which coincides with the 100th anniversary of the People's Republic of China (Official site of SRI, 2020). But together with the economic purposes, the BRI aims spreading the Chinese cultural and citizenship values over the local cultures of the countries involved by forming a common cultural space. Today China has already started a unique in its scope and analytics work, analyzing the legislation, social structure, behavioral habits and algorithms of the countries participating in the Project to develop common principles and models acceptable for use (the results of this work with specific recommendations for each country are planned for publication by the end of 2029).

The far-reaching, bold, and ambitious international trade network envisioned by General Secretary $\mathrm{Xi}$ is reminiscent of the ancient, unrivaled, and legendary Silk Road. The revival of the ancient trading route through the BR-Initiative is 
not only an ambitious economic trading proposal and a long term strategic geopolitical strategy, but it is also a major marketing tool to promote China throughout the world (Eberle, Bradley, \& Tafero, 2018).

This article aims to show how the Chinese government uses the BRI Project to demonstrate the achievements of Chinese society in social and cultural life, introduce the modern China to the world, level stereotypes about the Chinese worldview and lifestyle, which were formed in the world due to a certain isolation of China, lack of reliable information about China in the world and some other reasons. This huge amount of work in its long-term perspective has an idea of a unified "BRI culture" based on common economic goals and mutually beneficial cooperation construction, which would, to a certain extent, "insure" the economic interests and investments of the People's Republic of China into the economy of Silk Road as a road with an infrastructure as well as to the economy of the countries involved. At the article were used methods, typical for theoretical research: observation, analysis, synthesis, analogy, comparing, narration, conclusion making etc.

\section{Theoretical framework}

Cultural values are important factors that impact economic growth, international trade, marketing, finance, and politics. A deep and thorough understanding of cultural values is essential for success, failure to understand cultural values and their impact is a recipe for failure. Misunderstandings are more likely the larger the cultural differences, resulting in miscommunication, mix-ups, and unintended insults, creating stress between partner countries, and leading to a much higher cost of doing business and decreasing the chances of success in the relationship. When people in one country display norms, values, languages, communication patterns, and distinctive behaviors that do not match, and often may conflict with the norms, values, and behaviors in another country, additional time, resources, and effort are needed to overcome the differences. Consequently, there exists a preference for doing business with countries that have similar cultural values (Eberle, Bradley, \& Tafero, 2018).

Chinese, starting a new business, are not inclined to underestimate the importance of socio-cultural processes and foundations that exist in the format of "here and now." In these matters, they are of the opinion that culture is a reflection of the collective thinking of a particular nation as a whole and lays down social and behavioral algorithms for each adherent. Having understood and studied them, one can find the shortest and the most effective way to solve almost any problem at the new territory. In this regard, the study of cultural and social features of the territory always accompanies Chinese economic projects abroad. Also, traditional Chinese ethics suggests that it is the introduction of a new reality 
or algorithm into the culture that allows people to change their attitude to something. Therefore, the ability to influence the cultural and social background is considered an integral part of the Chinese innovations both within their own country and abroad.

China can protect its interests through an active presence in the countries involved in the Project (similar to the United States, which have their own military bases in different countries and thereby consolidate their presence in the region). But the Chinese have chosen the other way - to create a unified "BRI culture" based on common economic goals and mutually beneficial cooperation of the nations and peoples who take part in the Project.

The idea is to create a common cultural space around the Project, which, on the one hand, will connect the BRI Project participants at a deeper than financial gain. On the other hand, it will make the Project not only an interstate initiative, but also an internal concern of every country and nation. On the third, the Project will be autonomous that will minimize such risk factors traditional for interstate projects as the "change of power or political elites". Becoming supra-economic and supranational for any participating country, and for all together, the BRI Project (and with it the interests of the PRC) will be maximally protected from external influences.

Being quite immune to cultural and social innovations and changes in the new socio-cultural space, the Chinese are moving towards production of their own behavioral algorithms and their adaptation to new conditions. This, on the one hand, is explained by the longevity of Chinese traditional views throughout history, and on the other hand, by the Chinese traditional perception of change as chaos, leading to the destruction of an established system. That's why today the Chinese government pay much attention to introducing the traditional Chinese culture and modern Chinese social and cultural views to the countries that are involved into the BRI Project.

\section{«One belt - One road - One Civilization” concept}

Initially, the BRI Project aimed to create a railway system to accelerate the delivery of goods from China to Germany (Beijing and Berlin were originally seen as extreme points). Using this analogy (delivering goods from China to Europe by land rout), the BRI Project also got the informal name "New Great Silk Road". However, with time, there turned out to be an unspoken separation of the BRI Project components into "One Belt, One Road» as a pure economic project and the "New Great Silk Road" as a socio-cultural initiative. Considering the BRI Project as a common for all the countries one undoubtedly entails changes in the cultural background of the countries which territory the Project passes. In order to realize the economic and trade interests, which are laid down as the priority of 
the BRI Project, countries should, on the one hand, adapt and unify their own cultural and value background for the possibility of "friendship by economies" and in a certain way level down their own geo-political interests. On the other hand, it is necessary for the countries to open their own socio-cultural space both for nearby cultures (direct neighbors and closest partners in the Project), and for the cultural and value views of modern China as the main financial sponsor of the BRI Project. These objective issues help to enhance the multilateral cultural impact of the BRI Project over the cultural space of the countries involved. (Pourtajrishi \& Shirvani, 2018).

Since ancient times, the Silk Road has promoted not only economic, but also cultural interpenetration of various peoples. The idea of OBOR civilization was also conceived not only as an economic project, but also as a platform for social interaction. On this platform, various ethnic, religious and cultural traditions can merge together, thereby forming a new culture with new civilizational-value principles and guidelines. Traditionally cultural, religious and value principles of a nation (ethnic group, country) belonging to the sphere of collective unconscious and archetypal turn out to be a "foretaste stone" in such initiatives that unite many peoples and cultures (Roman Empire, British Empire, USSR, European Union etc.). Today, using the traditional name for the Project - New Great Silk Road China, as if, says: our system works and has proved its viability in various historical situations. We know how to make it for ourselves, and so we can do it for the whole OBOR Project family. Throughout its history, China has already proved that sometimes opposing and diverse elements of Chinese culture (Confucianism, Buddhism and Taoism) can be united united and form a common philosophical and cultural space. For 2500 years, Chinese culture was based on unified categories that did not contradict the views of each concept: to love the world, seek a quiet life, respect nature, strive for harmony, avoid extremes, not participate in ethnic and religious wars, respect the state and government, etc.

Using this positive experience, China seeks to revive the concept of the Great Silk Road Civilization and build a new civilization space along the OBOR Project. This will undoubtedly change the geo-cultural picture of the world and strengthen both the geo-civilizational role and influence of China. By investing and creating the New Great Silk Road Civilization as a cultural initiative, China hopes to create a community of interests and values that will protect China's economic interests and form a common economic system as a new form of interstate interaction.

China initiated the OBOR Project as a new form of relations between countries and peoples, a new civilizational model based on respect for local traditions and beliefs, peculiarities and habits. The main unifying principles in New Silk Road Civilization should be: China's non-interfering in the internal affairs of the states involved into the Project, obvious economic benefits for countries, implicit 
dominance of China and principles of collegiality in solving all the problems related to the Project. This principle during 5000 years allowed the Han people, as the Chinese-forming nation, successfully manage the Chinese state - a multinational, multicultural and multi-religious unit. Throughout the history of their existence, the Han people (who eventually became fully associated with the Chinese and China) managed even the farthest borders of their state and culturally influenced these areas.

Prime Minister Zhou Enlai proposed "harmony and goodwill” (Pourtajrishi \& Shirvani, 2018) as the main idea of peaceful coexistence inside the Project. President Xi Jinpin proposed "common interest" as the slogan of OBOR. Cooperation between peoples within the framework of OBOR Project should be based on the principles of peaceful coexistence, mutual concern, mutually beneficial cooperation and common development, which contribute to common prosperity. (Pourtajrishi \& Shirvani, 2018). Creating a new concept of culture - BRI culture (civilization) - China is trying to appeal to the emotional and social values of nations and peoples living along the New Silk Road. And, as it is known, these categories belong to public unconscious and form stronger and more stable motivational basis than just economic profit.

As it is planned by the PR China, China and the countries involved into the OBOR Project should jointly participate in geopolitical and geo-economic cooperation and form a community with common interests, values, culture and security. (Pourtajrishi \& Shirvani, 2018). At the same time, each of the countries autonomously acts on the world stage (the OBOR project does not impose restrictions over the countries as to their foreign policy and inner country strategies). This principle in particular distinguishes the OBOR Project as an allied unit from organizations like NATO, European Union, USSR etc. The New Silk Road Civilization is planned as a superstructure that independently acts on the international arena with the full autonomy of all the countries involved. The New Silk Road Civilization can be seen as a fundamentally new civilizational concept, based on the conscious choice of this form of interaction by all participants of the Project, unification of culturally unconscious archetypes of peoples and respect of countries to each other.

\section{Cultural component of Economic Projects}

Today China uses different sources to promote its own culture heritages and contemporary values over the world, through the BRI Project territory as well. Following the extended wording of the main goal as "One Belt - One Road - One Civilization" the country invested obligations to disseminate and proclaim Chinese social and cultural values in the form of cultural interaction with local cultures to the duties of official non-core organizations of a rather high level. 
Silk Road Chamber of International Commerce (SRCIC) is an interstate structure that includes national chambers of commerce of countries involved into the New Silk Road Project. SRCIC is headquartered in Hong Kong; the Secretariat is located in Xi'an with offices in Beijing and Shanghai. The number of SRCIC members is constantly growing and today it includes 218 organizational members from 82 countries (state-level chambers of commerce and their local representatives). 62 cities from 22 countries that have special status in the New Silk Road Project formed the Urban Alliance as an autonomous organization within the SRCIC Directorate. The goal of the SRCIC is to serve as a "bridge connecting enterprises and governments, providing a platform for collaboration between business associations and members of the OBOR Project”. (Official site of SRCIC, 2020). SRCIC plays a key role in promoting road construction, economic, cultural and social development of relationships within the Project with emphasis on mutual respect and the rule of law. Five sub-organizations also operate within SRCIC: "www.eSilkRoad.com" platform, International Silk Road Development Fund, International Art Center, New Silk Road Cultural Park and New Silk Road Transnational Financial Leasing Alliance. These organizations provide a platform for practical collaboration among SRCIC members. (Official site of SRCIC, 2020).

Silk Road Association is a registered international Civil Society Organization with non-profit and non-political status created to promote Silk Road civil society Initiatives in Asia CIS, Middle Eastern, Mediterranean and European countries having its regional offices located in France, Kazakhstan, Turkey, Hong Kong, SAR, PRC, Main land China and India. Silk Road Association is a member of various international organization, government institutions and chamber of Commerce of various Silk Road countries and has been instrumental in creating bridge between countries involved into the BRI Project for promoting cultural and educational programs, business, trade investments opportunities and promotion of sustainable green and smart city concepts sharing. The prime objective of Silk Road Association is to create platform for intergovernmental and intercultural communication within cities along the New Silk Road to enhance and revive and rejuvenate the ancient Silk Road by unveiling various civil society initiatives together. Since, ancient Silk Road was not only the main trading route of the world, but also a melting point of knowledge and cultures. Silk Road Association undertakes several initiatives to promote educational and cultural exchanges including people to people interactions between the countries involved into the OBOR Project (Official site of SRI, 2020).

OBOR Culture and Trade Association - is a nonprofit organization which consists of a group of abroad countries` businessmen who are interested in China. Through their presence and personal business relationships, they have an opportunity to promote their countries as perspective business partners for the Chinese 
government and non-government organizations. By forming a business network common platform, the Association aims to promote regional and cross-continental connectivity between countries and China, South East Asia and Eurasia. To support own business business, OBOR Culture and Trade Association provides social and cultural opportunities for countries involved into the OBOR Project. The Association gives opportunities for trade and other communications not only in "other countries` and China" perspective, but also to countries between each other without involving China. (Official site of OBOR CTA, 2020).

The organizations mentioned do not limit the amount of ones sponsored, organized or somehow in the other way supported by the Chinese government and local authorities to proclaim the Chinese culture idea through the official organizations, NGOs etc.

\section{Education opportunities for Chinese culture values promotion}

Understanding that BRI Project belongs to the sphere of global and longterm initiatives that will have a visible effect in 50-100 years, China wants to insure for itself the continuity of the course and ideas. The stake is placed on the young generation, which should consciously perceive the Project as the existing reality of the world, existing fact and an integral part of world and local economic systems (and not just economic necessity). It is such continuity that can ensure the constant renewal of the Project, despite the enormous amount of resources (political, financial, human, time, etc.) that are already and still to be spent by all the participants without any visible return. And in this matter, the Chinese went according to their well-developed scheme: through the system of education.

The PRC education system for a long time evolved in isolation from the idea of globalization and served to a greater extent the needs of the Chinese state than contributed to the development of a personality. Therefore, it is natural that in the situation of OBOR Project forcing, the higher education system, in particular, faced the internationalization problem which is seen as a requirement to the economic and social initiative declared implementation. Most Universities and institutions responsible for managing education in China recognize internationalization as an essential component of training qualified personnel process in the context of "One Belt, One Way" strategy. The PR China Ministry of Education sees high adaptability as possibility of student mobility programs' implementation, experience of studying in 2-3 universities (only 1 of which can be Chinese) during the period of study (experiencing of different educational systems), education and training of highly qualified specialists with knowledge in several areas, skills of creating and working in international professional teams as professional competencies of new specialists able to work for BRI Project. 
University Alliance of the Silk Road (UASR) - is a cross-university union centered at Xi'an Jiaotong University. The Alliance aims to support the BRI Project with specialized researches and to foster academic exchange between the countries involved. In particular the Alliance is to provide the OBOR Project with the legal support and to produce mechanisms to agree national legislations of the countries involved (by the means of law schools attached to the UASR) (Ma, 2016). Also the Alliance should create conditions for the Chinese higher education system internationalization and provide opportunities for the Chinese youth to get education in a Chinese and a foreign university at the same time. In addition, the UASR sponsors international cultural events including the UASR Educational Exhibition and Cultural Festival (Yojana, 2015) as well as other cultural events through the countries of BRI Project. It can be said, that this organization forms the strategy of cultural expansion of China through the countries of the Project. The UASR was founded in 2015 by uniting 100 universities from 22 countries. For now it includes 132 universities across 32 countries and regions on 5 continents (Martin, 2018).

Global-Silk Road University Consortium. In 2015, the Silk Road Association passed a resolution for the creation of GLOBAL - SRUC (Global-Silk Road University Consortium) a platform where elite universities along the Silk Road could become a member and these member universities together could create a platform where various academic exchanges could be derived for mutual benefits through scholarly interactions, cultural interchanges, cooperative research projects, Exchange of Undergraduate, Post Graduates students including academic staff, Setting up of Dual Degree Program for the Bachelor \& Master programs, Short Study Program, Semester Exchange Programs, Summer Programs. This initiative enables the students along the countries of Silk Road to pursue their academic studies with any academic institutions-members of the Global - SRUC (Silk Road University Consortium).

Confucious Institute - is a public educational organization under the Ministry of Education of the People's Republic of China. The Institute aims to promote Chinese language and culture, support learning and teaching of Chinese internationally and facilitate cultural exchanges. The Confucius Institute program began in 2004 and was initiated by Hanban (International Office of Chinese Language Council attached to Ministry of Education of the People's Republic of China). The Confucius Institute also has non-academic goals. The Economist says that the Confucius Institutes is "an important part of China's overseas propaganda set-up» (A message from Confucius: New ways of projecting soft power, 2009).Many foreign scholars characterize the CI program as an exercise in soft power, expanding China's economic, cultural, and diplomatic reach through the promotion of Chinese language and culture (Park, 2013), while others suggest a possible role of it in intelligence collection abroad (Pierrebourg \& Juneau-Katsuya, 2009). The 
CI works in co-operation with local affiliate colleges and universities around the world. It provides foreign partners with opportunities of cooperation, studying Chinese, awarding of students and teachers, exchange programs. Other CI initiatives include Chinese contemporary art exhibitions, television programs, concerts of popular singers, modern Chinese literature translations and the expansion of state-run news channels such as Xinhua News Agency and China Central Television. As of 2019, there are 530 Confucius Institutes in dozens of countries on six continents (Hanban-Confucius Institute, 2019), though the organization is constantly criticized due to concerns of rising Chinese influences in the countries in which it operates.

\section{Arts and music opportunities}

The Chinese use the OBOR Project opportunity to promote their culture very actively. In modern Chinese art a whole branch of "The Silk Road Art" appeared: it is designed to adapt the Chinese national musical, dance, choreographic, graphic traditions to the forms that foreigners are able to perceive. Gradually, China accustoms the world to its sound, plastic, color. Chinese cinemas are actively working with abroad local directors and actors, bringing to films not only the financial component, but also their own values and social touches. Contracts were made with leading cinematographic and animation associations to shoot products with the Chinese component (the animated films "Mulan”, "Everest”, films on historical subjects can be considered examples of such cooperation). China constantly organizes concerts and exhibitions in the BRI Project countries. According to promoters, the low cost of tickets (China pays $50-70 \%$ of the cost) and the high quality of events makes them "sold out" ones. The duties of students receiving a master's degree in art in foreign universities include the mandatory organization of several public events - concerts, exhibitions etc. (without proof of such activity, a master's degree will not be recognized at the Ministry of Education of the PRC). The Chinese are regular participants and diploma holders of art competitions of both local and the highest levels in the BRI Project countries. To familiarize the world with China, art tools are used to appeal to the emotions and soul of a person, which means that they remain in the emotional picture of a person as something pleasant that cannot but contribute to enhancing the image of Chinese culture and the PRC as a whole at the external arena.

\section{Conclusions}

The resurrection of the ancient Silk Road with the BR-Initiative is an ingenious move by China that illustrates China's ability for long-term strategic thinking and their vision for the future. Even if the BR-Initiative is only a moderate, or 
even minimal success, it will still be a great achievement. It will assure China's dominant role in the world economy for many years to come. How various countries will respond to either the success or failures over time will determine both the economic and geo-political changes that are certain to happen. The variety of cultural dimensions present in these nations will also influence dramatically this response. It cannot be over-emphasized that there is this influence and needs to be taken into consideration as a major factor beyond the economics of trade. To achieve this goal China uses a huge toolbox, acting in the long term perspective and with a soft invocation of the Chinese worldview and socio-cultural values as the basis for New Silk Road Civilization`s culture to appear. Appealing to cultural and value orientations of those countries that are involved in the Project, China seeks not only to establish its socio-economic initiative, but also to consolidate it, as if to "integrate" it into own cultural and value models and spaces of other peoples. Therefore, the cultural component in this case is not only equivalent to the economic one, but also to a large extent ensures the success of all economic initiatives of China abroad.

\section{References}

A message from Confucius: New ways of projecting soft power. (2009). The Economist. 22.10. Eberle, P., Bradley, Th., \& Tafero, A. (2018). A Cultural Perspective of China's Belt and Road Initiative: Impacts, Insights, and Implications. Journal of International Business and Cultural Studies, Vol.12.

HanBan-Confucius Institute. (2019). ClassRoom. english.hanban.org.

Kuo, L., \& Kommenda, N. (2018). What is China's Belt and Road Initiative? The Guardian. 5.09 .

Ma, L. (2017). University alliance seeks enhanced education co-op along Silk Road. China Daily.18.09.

Ma, L. (2016). Chinese and foreign law schools launch New Silk Road alliance. China Daily.18.09.

Martin, J. (2018). Washington University first North American member of the University Alliance of the Silk Road. Global. 18.09. Retrieved from https://global.wustl.edu/washington-university-first-north-american-member-university-alliance-silk-road/

Official site of Global Silk Road University Consortium. (2020). Retrieved from http://www.silkroadassociations.org/about-us/global-silk-road-university-consortium

Official site of OBOR CTA. (2020). Retrieved from http://obor.my/en/home/

Official site of SRCIC. (2020). Retrieved from http://www.srcic.com/srcic-profile/

Official site of SRI. (2020). Retrieved from http://www.silkroadassociations.org/about-us/index

Park, J. (2013). Cultural artifact, ideology export or soft power? Confucius Institute in Peru. International Studies in Sociology of Education, 23(1).

Pierrebourg, F., \& Juneau-Katsuya, M. (2009). Nest of Spies: The Startling Truth About Foreign Agents at Work within Canada's Borders. HarperCollins Canada. 317. 
Pourtajrishi, V., \& Shirvani, El. (2018). Cultural considering New Silk Road: One Belt One Road One Culture. Tehran Times. 21.02. Retrieved from https://www.tehrantimes.com/news/421446/Cultural-considering-New-Silk-Road-One-Belt-One-RoadOne-Culture

Winter, T. (2016). One Belt, One Road, One Heritage: Cultural Diplomacy and the Silk Road. The Diplomat.29.03 Retrieved from https://thediplomat.com/2016/03/one-belt-one-roadone-heritage-cultural-diplomacy-and-the-silk-road/

Yojana, Sh. (2015). University collaboration takes the Silk Road route. University World News. 07.02. Retrieved from https://www.universityworldnews.com/post.php?story=2015 0611130705830 